\title{
Defeitos Cirúrgicos Nasais: Reconstrução com Retalho de PENG Modificado
}

\section{Nasal Surgical Defects: Reconstruction with Modified PENG Flap}

Ermelindo Tavares ${ }^{1}$, Paula Maio ${ }^{1}$

\section{RESUMO}

INTRODUÇÃO: O retalho de Peng consiste numa modificação "em pinça" do retalho de Rintala e tem como finalidade o encerramento de defeitos cirúrgicos da ponta e do terço distal do dorso do nariz. Foi descrito inicialmente por Peng (retalho de Peng clássico) e revisto, posteriormente, por Rowe e Ahern (retalho de Peng modificado).

O nosso objetivo foi fazer uma revisão teórica sobre o retalho de Peng (clássico e modificado) e relato dos resultados obtidos com a técnica de Ahern.

MATERIAL E MÉTODOS: Três doentes foram submetidos à exérese de cancro cutâneo do nariz. A reconstrução foi feita com retalho de Peng modificado (técnica de Ahern). As cirurgias foram executadas num tempo operatório e sob anestesia local.

RESULTADOS: Foram obtidos bons resultados funcionais e estéticos. Não se registaram complicações.

DISCUSSÃO: O retalho de Peng é um procedimento com grande utilidade na reconstrução da ponta e dorso distal do nariz. A técnica de Ahern é a que apresenta maior dinamismo (mobilização da pele nasal e malar), versatilidade (encerramento de defeitos laterais e medianos) e capacidade de preservação da anatomia e estética nasal (incisões na junção das subunidades nasais e unidades faciais). Os procedimentos são exequíveis num único tempo operatório e sob anestesia local. O comprometimento parcial ou total do retalho raramente acontece, em particular com modificações introduzidas por Ahern.

CONCLUSÃO: O retalho de Peng modificado (técnica de Ahern) demonstrou ser eficaz, seguro e boa alternativa às modalidades clássicas usadas na reconstrução da ponta do nariz, nos três casos.

PALAVRAS-CHAVE: Neoplasias da Pele; Neoplasias do Nariz; Retalhos Cirúrgicos; Rinoplastia; Transplante de Pele 


\section{ABSTRACT}

INTRODUCTION: The Peng flap is a pinch modification of linear advancement flap (Rintala flap). Its purpose is to close surgical defects in the tip and distal dorsum of the nose. It was initially described by Peng (classic Peng flap) and revised, later, by Rowe and Ahern (modified Peng flap).

Our objective was to describe classic and modified Peng flap (Rowe's and Ahern's techniques), and we report the results achieved according to Ahern's technique.

MATERIAL AND METHODS: Three cases of reconstruction of skin defects in the nose were performed using the modified Peng flap (Ahern's technique). All the patients had skin cancer. The surgery was executed in single operative time under local anaesthesia.

RESULTS: Good functional and aesthetic results were achieved. There were no complications.

DISCUSSION: Ahern's technique is the one that shows greater dynamism (mobilization of the nasal and malar skin), versatility (closure of lateral and median defects) and capacity to preserve the nasal anatomy and aesthetic (incisions at the junction of the nasal subunits and facial units). In general, the procedures are feasible in a single operative time under local anaesthesia. Partial and total flap failure is uncommon, particularly with Ryan's technique.

CONCLUSION: The Peng modified flap (Ahern's technique) revealed to be effective, safe and a good alternative to the classic modalities performed in the reconstruction of the nasal tip.

KEYWORDS: Nose Neoplasms; Rhinoplasty; Skin Neoplasms; Skin Transplantation; Surgical Flaps

\section{INTRODUÇÃO}

O cancro cutâneo engloba dois grandes grupos de neoplasia: o melanoma (proliferação anómala dos melanócitos dérmicos) e o não melanoma (proliferação anómala dos queratinócitos epidérmicos). Este último é o mais prevalente e, dentro do mesmo, o carcinoma basocelular e espinocelular são os mais frequentes. ${ }^{1} \mathrm{O}$ nariz é a unidade facial com função importante em termos estético e funcional, estando sujeito aos diferentes traumatismos devido à sua localização central e à falta de proteção natural. A radiação ultravioleta é um dos agressores mais comuns e importantes, tornando este órgão um dos locais faciais prediletos para o aparecimento de cancro cutâneo. ${ }^{2,3}$

O encerramento de defeito cirúrgico nasal de etiologia oncológica exige reparação da pele (revestimento externo) e, em certos casos, da mucosa (revestimento interno) e da estrutura cartilagínea (suporte). Esta abordagem com base no conhecimento da anatomia e fisiologia deste órgão denomina-se reconstrução tridimensional. Em adição, Burget e Menick introduziram o conceito da quarta dimensão, ou seja, a obtenção dum resultado estético próximo do normal. ${ }^{4}$ Esta meta, embora desafiante, deve ser alcançada, sempre que possível, em todos os casos. Para isso, torna-se fundamental conhecer e respeitar o princípio das subunidades nasais (subdivisão em asas, triângulos moles, columela, ponta, vertentes e dorso) também introduzido pelos dois autores. ${ }^{5}$
Os métodos de reconstrução nasal incluem o encerramento direto, os retalhos (avanço, rotação e transposição), os enxertos cutâneos (parcial e total) e compostos (pele e cartilagem) e a cicatrização por segunda intenção. O retalho de Rintala (RR) é um procedimento clássico e bem reconhecido que consiste num retalho retangular, linear e deslizante, utilizado no encerramento dos defeitos do dorso e ponta nasal. ${ }^{6}$ O retalho de Peng (RP) clássico é definido, em termos globais, como uma modificação "em pinça" da extremidade inferior do RR cuja finalidade é a reconstrução da ponta e do terço distal do dorso do mesmo órgão. Foi descrito por Peng7 em 1987 e revisto em alguns aspetos técnicos, posteriormente, por Rowe ${ }^{8}$ e Ahern 9 (retalho de Peng modificado).

Os objetivos deste artigo compreendem a descrição dos retalhos de Rintala e Peng (clássico e modificado), a apresentação dos resultados obtidos em três doentes tratados com a técnica de Ahern e a discussão tendo como foco os três métodos e as alternativas usadas na reconstrução da ponta do nariz.

\section{RETALHO DE RINTALA}

O RR (Fig. 1) é executado da seguinte forma: a neoplasia é removida de forma circular, oval, quadrangular ou retangular. A incisão do retalho começa nas faces laterais ou superior do defeito e prossegue para cima até à glabela; seguem-se a dessecação e o descolamento ao nível 


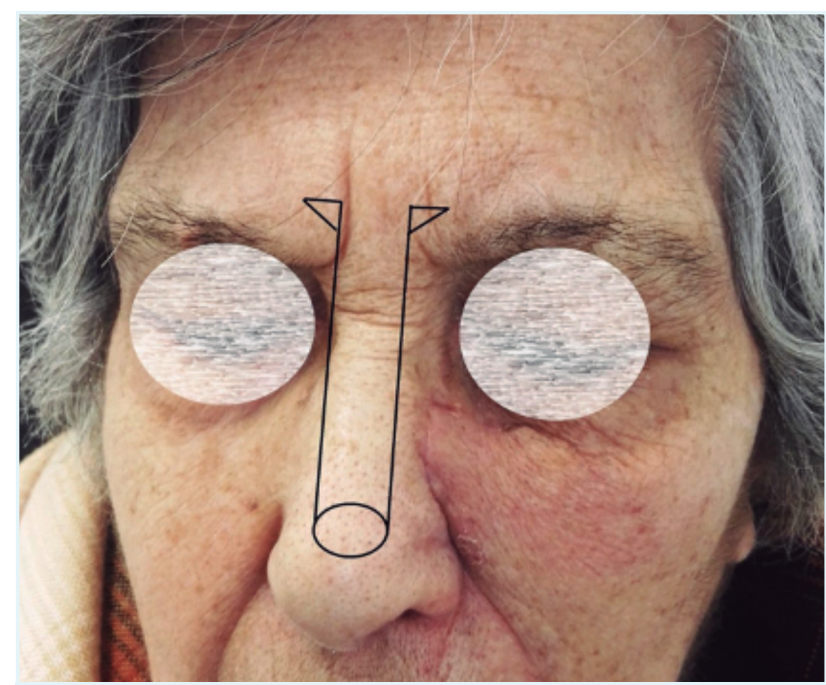

FIGURA 1. Delineamento do retalho de Rintala.

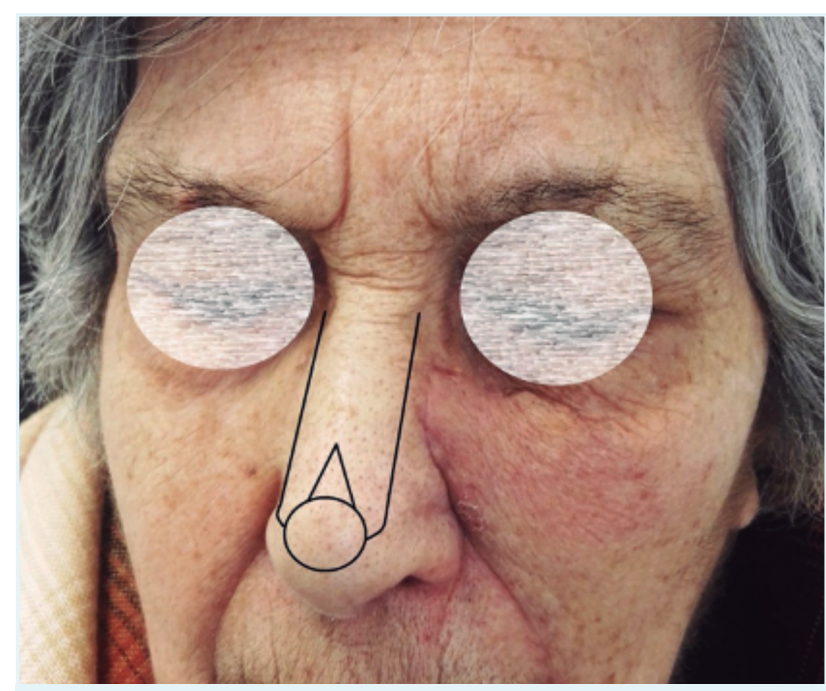

FIGURA 2. Delineamento do retalho de Peng clássico.

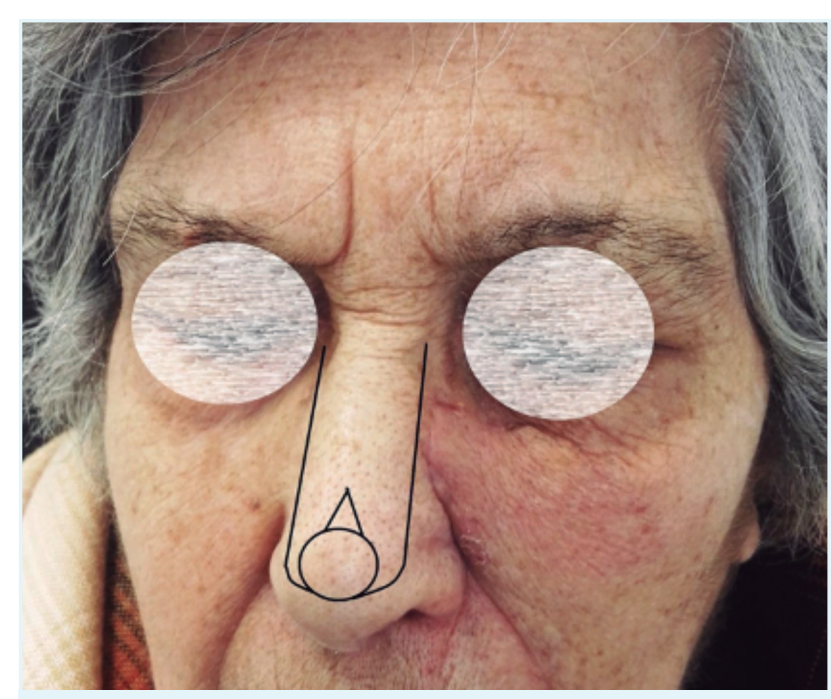

FIGURA 3. Delineamento do retalho de Peng modificado (técnica de Rowe).

do tecido adiposo subcutâneo e o levantamento do corpo. Na extremidade superior é colocado um triângulo de Burow em cada lado que irão permitir o avanço, com o mínimo de tensão. Por fim, faz-se adaptação e sutura no defeito, evitando sempre o efeito em tenda.

\section{RETALHO DE PENG CLÁSSICO}

O RP clássico (Fig. 2) é executado de forma idêntica ao RR, mas com algumas modificações introduzidas por Peng. A incisão começa ao nível da porção mediana da face lateral do defeito e avança até à região ântero-inferior do canto interno do olho. Segue-se a dissecação dum triângulo de vértice superior com ângulo de $30^{\circ}$ no topo do defeito (correspondente à face inferior do retalho), originando dois pequenos retalhos laterais ou "braços" (modificação "em pinça"). Por fim, faz-se a rotação interna destes dois últimos para a projeção duma nova ponta que desliza inferiormente e é suturado na base do defeito. A introdução de triângulos de Burow ou remoção do excesso de tecido nos cantos internos dos olhos pode ser necessário em alguns casos.

\section{RETALHO DE PENG MODIFICADO TÉCNICA DE ROWE}

A modificação de Rowe e colaboradores consistiu em iniciar a incisão dos dois "braços" do retalho na extremidade inferior das faces laterais do defeito (Fig. 3). ${ }^{8} \mathrm{~A}$ restante execução é idêntica ao RP clássico.

\section{TÉCNICA DE AHERN}

As modificações introduzidas por Ahern e colaboradores (Fig.s 4 e 5) baseiam-se na mobilização da pele das vertentes nasais, da região malar e, em menor grau, da glabelar. $O$ descolamento do retalho é executado ao nível submuscular, abaixo do músculo nasal. ${ }^{9}$

A incisão dos "braços" começa na extremidade inferior do defeito, tal como na técnica de Rowe. Esta prossegue posteriormente no sulco alar até atingir a junção entre a vertente nasal e a região malar; a partir deste ponto adquire orientação superior, paralela e ao longo dessa união e termina na área ântero-inferior dos cantos internos dos olhos. $O$ passo seguinte consiste na remoção da pele correspondente ao cone ou triângulo central. $\bigcirc$ vértice superior deste deve ter orientação vertical, nos defeitos cirúrgicos de localização mediana (Fig. 4) ou oblíqua e ao longo do "braço" de maior largura, nos excêntricos (Fig. 5). Segue-se a sutura interna da extremidade inferior do retalho na base do defeito, das suas faces mediais (local de remoção do cone) e, por fim, das laterais, após deslizamento da pele geniana. A colocação de triângulos de Burow ou subtração do excesso de pele no canto interno e a eliminação de crescente de dimensão variável ao longo da base da asa do nariz podem ser necessários. Por fim, realiza-se a sutura externa de todos os componentes. 


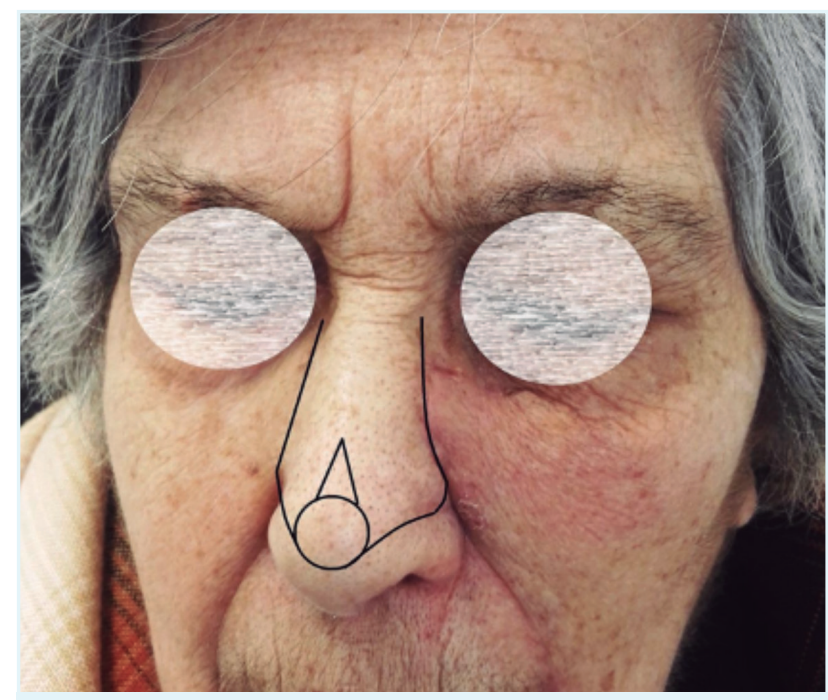

FIGURA 4. Delineamento do retalho de Peng modificado (técnica de Ahern) para os defeitos medianos.

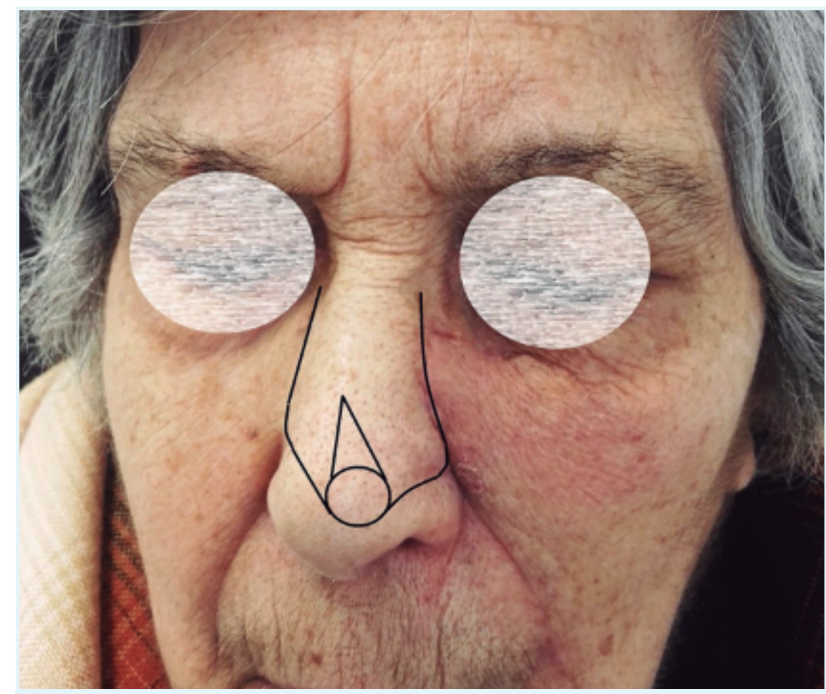

FIGURA 5. Delineamento do retalho de Peng modificado (técnica de Ahern) para os defeitos paramedianos.

\section{MATERIAL}

\section{CASO 1}

Mulher, caucasiana, de 68 anos, sem história laboral de exposição ultravioleta crónica e antecedentes pessoais irrelevantes. Negava medicação habitual e hábitos tabágicos. Referenciada por mancha pigmentada com 1,0 por $0,7 \mathrm{~cm}$, assimétrica, bordos irregulares, cor variegada, localizada quase paramedianamente na parte superior esquerda da ponta do nariz (Fig. 6a). A evolução era desconhecida. A dermatoscopia revelou estruturas romboides, aberturas foliculares com pigmentação assimétrica e pontos acinzentados. Colocaram-se como hipóteses de diagnósticos lentigo maligno e lentigo maligno melanoma. Não tinha lesões satélites, em trânsito e adenopatias regionais palpáveis. Foi realizada biópsia incisional que revelou lentigo maligno.

\section{CASO 2}

Mulher, caucasiana, de 70 anos, agricultora reformada, com antecedentes pessoais de hipertensão arterial essencial e diabetes mellitus tipo 2. Encontrava-se medicada com metformina e perindopril/indapamida. Negava hábitos tabágicos. Observada por placa cutânea não ulcerada, com 1,0 por 0,5 cm e bordos perolados, localizada na parte superior e paramediana direita da ponta do nariz (Fig. 7a). Desconhecia o tempo de evolução. A dermatoscopia demonstrou glóbulos pigmentados irregulares e estruturas vasculares arboriformes. Colocou-se como hipótese de diagnóstico carcinoma basocelular e a confirmação foi obtida por exame histológico (biópsia incisional).

\section{CASO 3}

Mulher, caucasiana, de 86 anos, agricultora reformada, portadora de pacemaker, com antecedentes pessoais de carcinoma espinocelular do lábio inferior, adenocarcinoma do reto e hipertensão arterial essencial. Encontrava-se medicada com ácido acetilsalicílico e irbesartan/hidroclorotiazida. Recorreu à consulta por lesão cutânea redonda, com 1,0 cm e ulcerada, envolvendo quase medianamente a parte superior da ponta do nariz (Fig. 8a). A evolução era desconhecida. Foram observadas crostas hemorrágicas e estruturas vasculares ramificadas à dermatoscopia. Colocou-se como hipótese de diagnóstico carcinoma basocelular. A confirmação foi obtida histologicamente após biópsia incisional.

\section{MÉTODO CIRÚRGICO}

O RP modificado (técnica de Ahern) foi a modalidade reconstrutiva adotada nos três casos. As cirurgias foram executadas num tempo operatório e sob anestesia local com mistura de lidocaína 2\% e epinefrina 1:100 000 (bloqueio nervoso infratroclear, infraorbitário e etmoidal anterior). As neoplasias foram excisadas de forma oval (Fig. 7b) e pentagonal (Fig.s 6b e 8b). Neste último, as faces laterais e inferiores são paralelas aos contornos das vertentes e asas nasais, respetivamente. Foram preconizadas margens laterais de 0,5 cm e profundas até plano muscular e pericôndrio alar. Foi realizado esvaziamento tecidual do espaço interalar e, posteriormente, a junção cautelosa das mesmas com sutura interna absorvível 5-0.

O retalho foi delineado e executado como mencionado anteriormente (Fig.s 6b-d, Fig.s 7b-d e Fig. 8c). Nos casos 1 e 3 os defeitos cirúrgicos tinham localização quase mediana (Fig.s 6b e 8b) e no 2 era excêntrica (Fig. 7b). Como tal, nestes dois primeiros o triângulo central foi excisado na direção vertical (Fig.s 6b-d e Fig. 8c) e no 

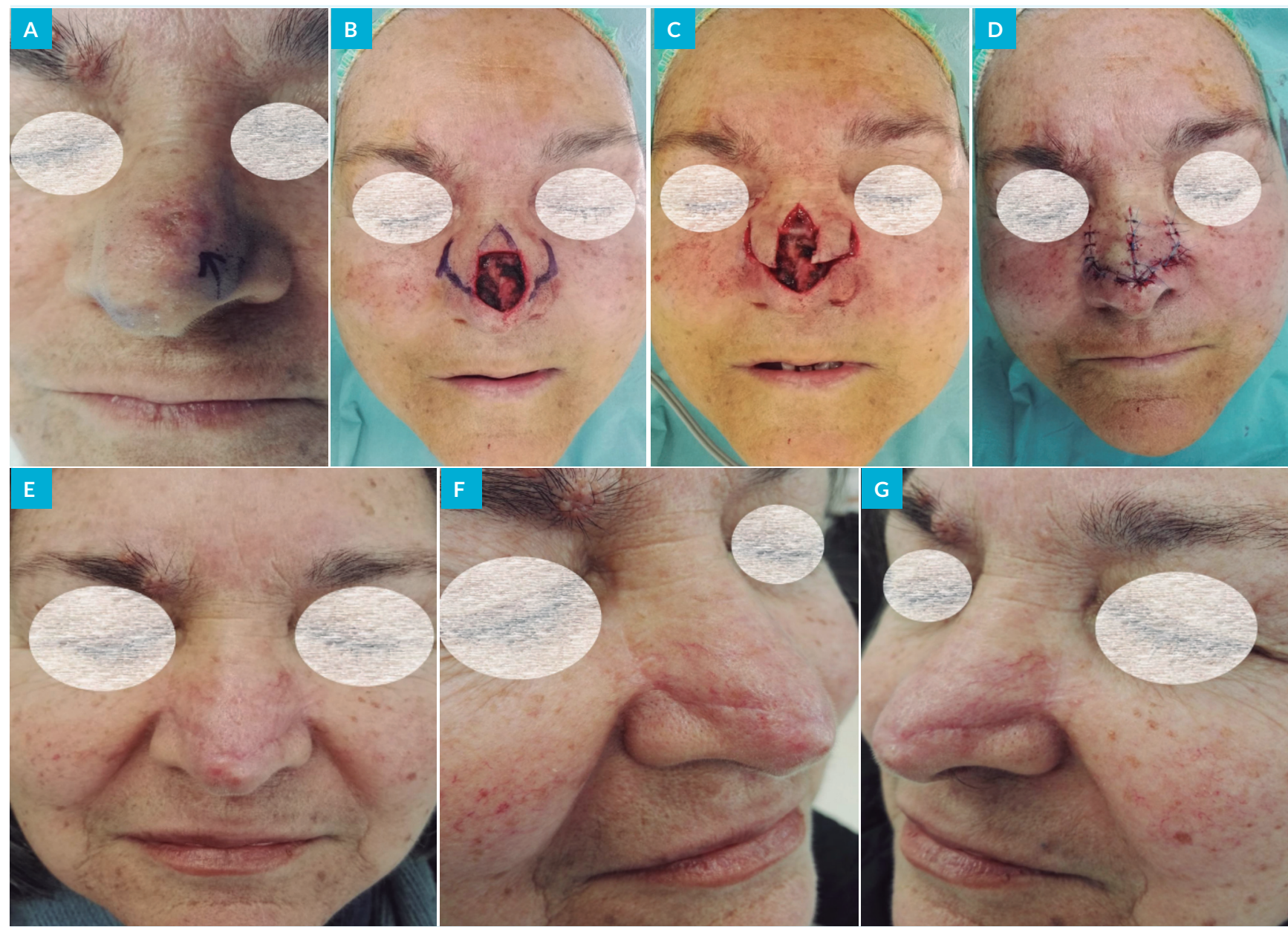

FIGURA 6 I CASO 1. Lentigo maligno do nariz (a). Defeito cirúrgico pentagonal com as incisões paralelas aos contornos das subunidades nasais (asas e vertentes) (b). Delineamento do retalho de Peng modificado de acordo com a técnica de Ahern (b). Dissecação no plano submuscular (c). Remoção do cone central na direção vertical, com obtenção dos dois "braços" rotacionais (c). Resultado imediato (d). Resultado tardio após 8 semanas (e-g).

segundo na oblíqua ao longo do braço mais largo (Fig.s 7b-d). Nos casos 2 e 3 foram removidos pequenos crescentes bilaterais na base da asa do nariz (Fig.s 7c-d e Fig. 8c). Em nenhum caso foi necessário eliminar o excesso de pele ou colocar triângulos de Burow nos cantos mediais oculares. $\bigcirc$ encerramento interno foi realizado com fio de sutura absorvível 4-0 e o externo com não absorvível 5-0 que foram removidos ao oitavo dia pós-operatório.

\section{RESULTADOS}

O diâmetro médio dos defeitos cirúrgicos foi de 2,1 por 1,8 cm. Não se registaram hemorragia, isquemia, necrose, deiscência, infeção e hematoma no pós-operatório. Foram alcançados bons resultados cosméticos e mantida a permeabilidade dos orifícios e cavidades nasais (Fig.s 6e-g, Fig.s 7e-g e Fig.s 8d-f). Nenhum caso desenvolveu efeito em alçapão ou elevação da ponta e asa do nariz. Os exames histológicos das peças operatórias revelaram exérese completa das neoplasias malignas. Todos os doentes permanecem em seguimento regular e sem recidivas.

\section{DISCUSSÃO}

O RR é uma técnica com grande reconhecimento na cirurgia reconstrutiva nasal. Tal como acontece com outros retalhos nasais, a sua escolha e delineamento são influenciados por fatores como o tamanho e localização do defeito cirúrgico, a lassidão tecidual, a disponibilidade de tecido adjacente e os hábitos tabágicos.,10 A sobrevivência da maior parte dos retalhos, em qualquer localização, varia na proporção inversa com o seu comprimento e direta com a sua largura. De acordo com Peng, um defeito do nariz com $1,0 \mathrm{~cm}$ requer, para o seu correto encerramento, um RR com cerca de 3 a 3,5 cm e um RP com 1,5 a 1,8 cm. ${ }^{7}$ As modificações "em pinça" introduzidas no RR tiveram resultados notáveis. Primeiro, permitiram melhorar, de forma substancial, a taxa de sobrevivência do mesmo, ao aumentar a sua largura e reduzir o seu comprimento para cerca de metade. Segundo, obteve-se um retalho "híbrido" composto por dois componentes, nomeadamente o unilateral (de avanço) e os bilaterais ou "braços" (de rotação). A rotação medial e a junção destes dois últimos permitem criar uma "nova 

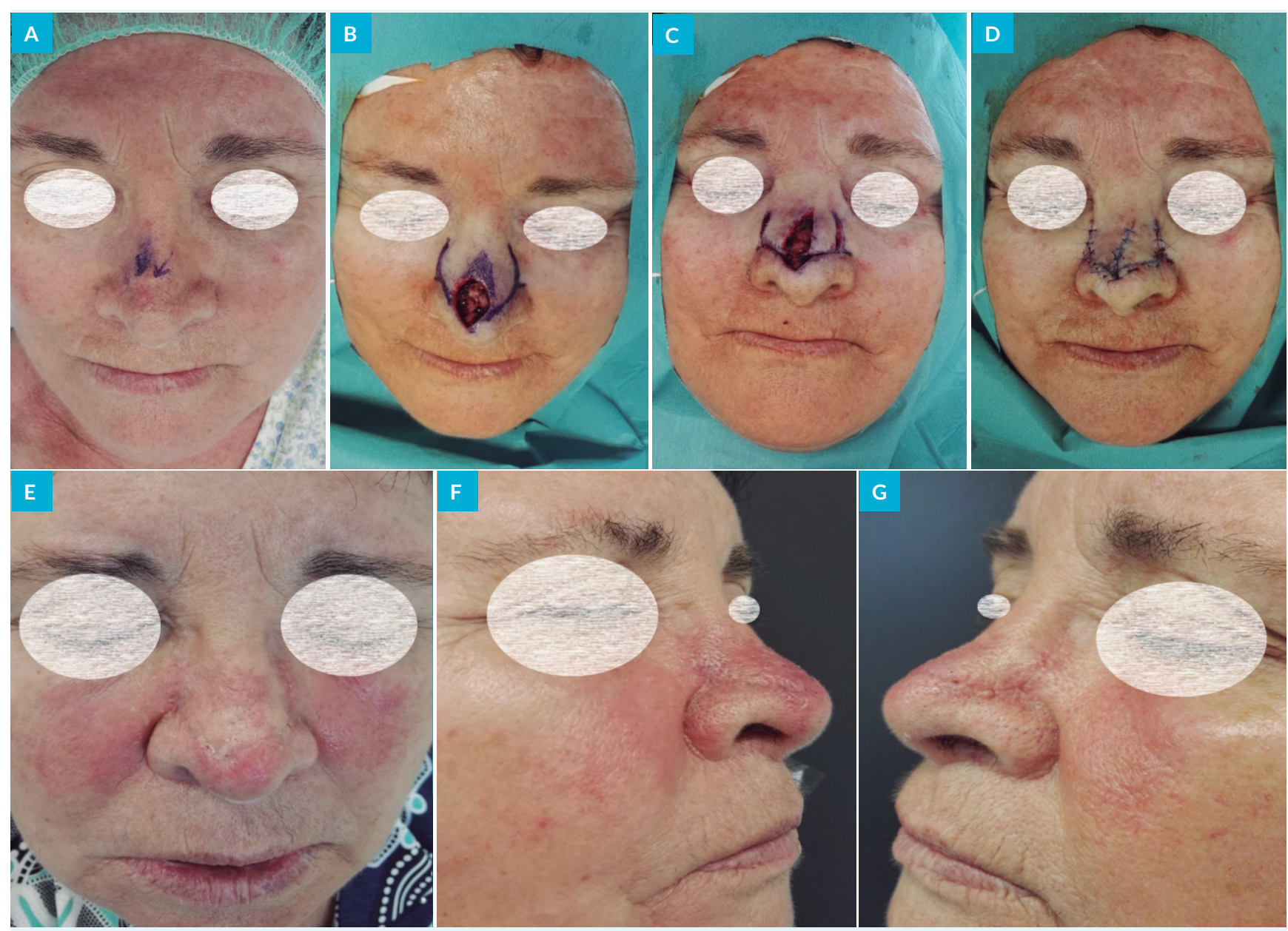

FIGURA 7 I CASO 2. Carcinoma basocelular do nariz (a). Defeito cirúrgico oval (b). Delineamento do retalho de Peng modificado de acordo com a técnica de Ahern (b). Dissecação no plano submuscular (c). Remoção do cone central na direção oblíqua ao longo do "braço" mais amplo (c). Resultado imediato (d). Resultado tardio após 6 semanas (e-g).

ponta" de configuração convexa e de fácil adaptação no defeito cirúrgico. ${ }^{8}$

As revisões efetuadas posteriormente no RP clássico também contribuíram, de forma inequívoca, para o seu aperfeiçoamento. Rowe e coautores propuseram iniciar a incisão dos "braços" na extremidade distal do defeito, assegurando aumento no comprimento dos mesmos e redução no deslizamento do componente unilateral. Desta forma, há redução no avanço e na distorção anatómica glabelar e menor tensão pedicular. ${ }^{8} \mathrm{Na}$ técnica de Ahern e colaboradores, a incisão começa no mesmo local supramencionado e continua ao longo das junções entre as subunidades estéticas nasais (vertente e asa) e unidades faciais (nariz e região malar). Deste modo, há camuflagem mais adequada das cicatrizes e obtenção de melhores resultados cosméticos. Além disso, há maior sobrevivência do retalho uma vez que as suas extremidades inferiores e superiores são mais amplas. ${ }^{?}$ Adicionalmente, a colocação dos cones centrais na direção vertical e oblíqua ao longo do braço de maior largura permite manter esta largueza inferior.
A dissecação do retalho ao nível do plano submuscular é outra característica importante na técnica de Ahern. Esta atitude permite manter um suprimento sanguíneo adequado e mobilizar o retalho com pouca ou nenhuma tensão. É também crucial referir que existem outras particularidades referidas pelos autores para uma boa execução técnica. Primeiro, a realização das suturas internas das faces laterais às regiões malares depois da remoção dos cones centrais, da inserção dos "braços" na extremidade inferior do defeito cirúrgico e do encerramento profundo das faces mediais e laterais do retalho. Deste modo, evitam-se o desalinhamento, a distorção e a tensão pedicular. Segundo, a remoção de pequeno crescente ao longo da base da asa do nariz nos casos de avanço geniano extenso, com o intuito de impedir distorção labial superior e do sulco nasogeniano. Por fim, sempre que possível, recorrer às técnicas de sutura para colmatar o excesso de tecido na região do canto ocular medial, em vez da excisão cutânea ou triângulo de Burow. Nos doentes tratados neste artigo estes pormenores foram tidos em consideração. 

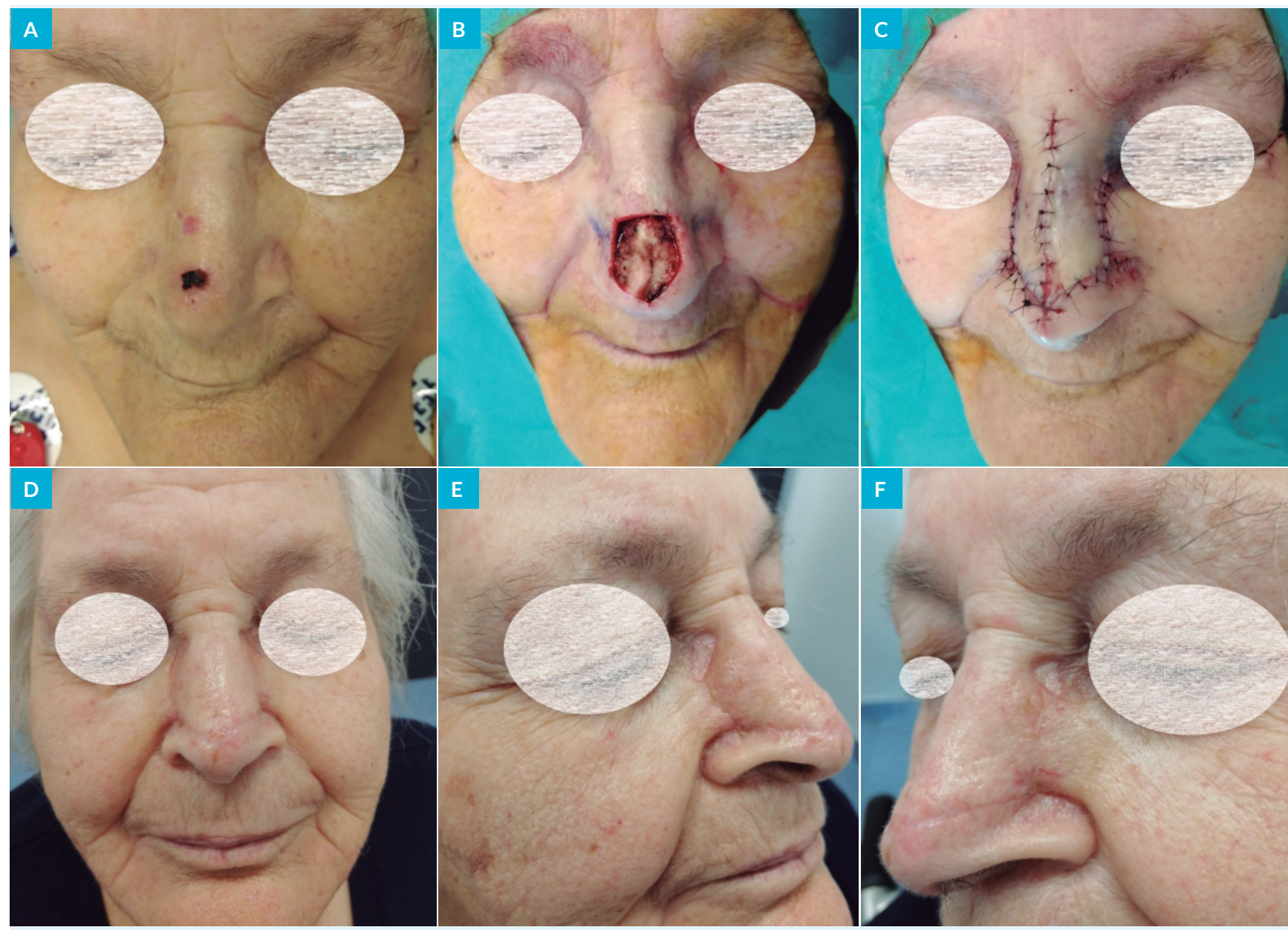

FIGURA 8 | CASO 3. Carcinoma basocelular do nariz (a). Defeito cirúrgico pentagonal com as incisões paralelas aos contornos das subunidades nasais (asas e vertentes) (b). Resultado imediato (c). Resultado tardio após 6 semanas (d-f).

Na literatura médica são escassos os relatos de falência total dos retalhos de Peng, perante uma boa execução técnica. $8,9,11,12$ As técnicas clássica e modificadas permitem reconstruir defeitos de espessura cutânea total da ponta e/ou dorso distal, de médias dimensões, localizadas mediana e paramedianamente e com manutenção da cor, textura e estruturas pilossebáceas. O diâmetro médio dos defeitos referido neste artigo (cerca de $2 \mathrm{~cm}$ ) é próximo do observado em algumas publicações. ${ }^{8,9,11} \mathrm{~A}$ maior parte dos defeitos envolvendo mais de metade da ponta e/ou cartilagem devem ser reconstruídos com outros métodos, nomeadamente o enxerto de pele total, o retalho interpolado frontal e nasogeniano, com ou sem enxerto cartilagíneo, ou outras técnicas. A elevação da ponta nasal, a assimetria das narinas e a anestesia distal transitória por secção do ramo nervo etmoidal anterior podem ocorrer em alguns casos. ${ }^{9,13} \mathrm{Em}$ nenhum dos três doentes relatados ocorreram estas complicações estéticas, até ao momento.

A hemorragia é também uma complicação comum e geralmente transitória. Os doentes medicados com anticoagulantes orais e antiagregantes plaquetares ou com distúrbios da coagulação são os mais afetados. 0 hematoma e a infeção são pouco comuns e podem comprometer de forma parcial ou total a sobrevivência dos retalhos. Tal como Ahern, os autores advogam a utilização de suturas externas descontínuas, em particular nos intervencionados de maior risco, uma vez que podem ser retirados parcialmente para permitir a drenagem de hematomas e abcessos. Além disso, as hemostases intraoperatórias devem ser minuciosas, assim como a monitorização pós-operatória antes da alta clínica. A antibioterapia profilática não é recomendada na maior parte dos doentes com feridas limpas. É de salientar, de novo, a ausência destas complicações neste relato clínico.

Os exemplos de procedimentos alternativos para o encerramento dos defeitos cirúrgicos da ponta nasal incluem o retalho de Rintala, ${ }^{6}$ o bilobulado (RB), ${ }^{14,15}$ O paramediano frontal clássico (RPFC) ${ }^{16}$ e tunelizado (RPFT), ${ }_{17}^{17}$ o nasogeniano (RNG) ${ }^{18}$ e o enxerto de pele total $(E P T)^{19}$ e composto contendo pele e cartilagem (EC). ${ }^{20}$ Em comparação ao RP modificado (técnica de Ahern), os inconvenientes incluem: violação do princípio das subunidades nasais (RB), maior risco de necrose, em particular, nas extremidades (RB, retalhos frontais, EPT, EC) efeito em alçapão (RB, retalhos frontais, RNG), dois 
tempos operatórios (RPFC), perda da textura, cor (alguns casos) e estruturas pilossebáceas nasais (retalhos frontais, RNG, EPT, EC), morbilidade superior (RPFC), deformidades cicatriciais na região frontal (retalhos frontais), apagamento e assimetria do sulco nasogeniano (RNG), hipertricose iatrogénica (RNG, retalhos frontais, EPT) e desvio da ponta e/ou asa nasal (RNG, EC, retalhos frontais). Em contrapartida, com exceção do RB, todas permitem reconstruir defeitos com mais de $2 \mathrm{~cm}$ de diâmetro.

\section{CONCLUSÃO}

O retalho de Peng modificado (técnica de Ahern) é método cirúrgico munido de singularidade, dinamismo, versatilidade e grande capacidade de preservação da estética, função e arquitetura tridimensional do nariz. As complicações pós-operatórias são pouco frequentes. Como tal, trata-se duma boa alternativa aos procedimentos clássicos na reconstrução dos defeitos da ponta e dorso distal do nariz.

\section{AGRADECIMENTOS / ACKNOWLEDGMENTS}

Serviço de Anatomia Patológica e equipa de enfermagem e assistentes técnicos e operacionais do Bloco Operatório Central e da Consulta Externa, Hospital Vila Franca de Xira.

\section{RESPONSABILIDADES ÉTICAS}

CONFLITOS DE INTERESSE: Os autores declaram a inexistência de conflitos de interesse na realização do presente trabalho.

FONTES DE FINANCIAMENTO: Não existiram fontes externas de financiamento para a realização deste artigo.

CONFIDENCIALIDADE DOS DADOS: Os autores declaram ter seguido os protocolos da sua instituição acerca da publicação dos dados de doentes.

PROTEÇÃO DE PESSOAS E ANIMAIS: Os autores declaram que os procedimentos seguidos estavam de acordo com os regulamentos estabelecidos pelos responsáveis da Comissão de Investigação Clínica e Ética e de acordo com a Declaração de Helsínquia da Associação Médica Mundial.

PROVENIÊNCIA E REVISÃO POR PARES: Não comissionado; revisão externa por pares.

\section{ETHICAL DISCLOSURES}

CONFLICTS OF INTEREST: The authors have no conflicts of interest to declare.

FINANCING SUPPORT: This work has not received any contribution, grant or scholarship

CONFIDENTIALITY OF DATA: The authors declare that they have followed the protocols of their work center on the publication of data from patients.

PROTECTION OF HUMAN AND ANIMAL SUBJECTS: The authors declare that the procedures followed were in accordance with the regulations of the relevant clinical research ethics committee and with those of the Code of Ethics of the World Medical Association (Declaration of Helsinki).

PROVENANCE AND PEER REVIEW: Not commissioned; externally peer reviewed.

\section{REFERÊNCIAS}

1. Skin cancer - How diet, nutrition and physical activity affect skin cancer risk. World Cancer Research Found. [Accessed April 22, 2020] Disponível em: https://www.wcrf.org/dietandcancer/skin-cancer.

2. Choi JH, Kim YJ, Kim H, Nam SH, Choi YW. Distribution of Basal Cell Carcinoma and Squamous Cell Carcinoma by Facial Esthetic Unit. Arch Plast Surg. 2013; 40: 387-91. doi: 10.5999/ aps.2013.40.4.387.

3. Oda T, Kato H, Watanabe S, Morita A. Facial site distribution of basal cell carcinoma in Japanese. Exp Dermatol. 2019; 28 Suppl 1:69-71.

4. Burget GC, Menick FJ. Nasal reconstruction: seeking a fourth dimension. Plast Reconstr Surg. 1986; 78: 145-57.

5. Burget GC, Menick FJ. The subunit principle in nasal reconstruction. Plast Reconstr Surg. 1985; 76: 239-47.

6. Onishi K, Okada E, Hirata A. The Rintala flap: a versatile procedure for nasal reconstruction. Am J Otolaryngol. 2014; 35: 577-81. doi: 10.1016/j.amjoto.2014.06.002.

7. Peng VT, Sturm RL, Marsh TW. "Pinch Modification" of the Linear Advancement FlapJ Dermatol Surg Oncol. 1987; 13: 251-53.

8. Rowe D, Warshawski L, Carruthers A. The Peng flap. The flap of choice for the convex curve of the central nasal tip. Dermatol Surg. 1995; 21: 149-52.

9. Ahern RW, Lawrence N. The Peng flap: reviewed and refined. Dermatol Surg. 2008; 34: 232-37.

10. Hwang K, Son JS, Ryu WK. Smoking and flap survival. Plast Surg. 2018; 26: 280-85. doi: 10.1177/2292550317749509.

11. César AJF, Barros AM, Santos PH, Azevedo FM. Reconstructing surgical defects of the nasal tip in a single-stage procedure. Surg Cosmet Dermatol. 2016; 8: 357-60.

12. Deluca J, Tappeiner L, Pichler M, Eisendle K. Using the Peng flap for a wide dorsal nasal defect. J Dtsch Dermatol Ges. 2014;12:1060-62. doi: 10.1111/ddg.12360.

13. Paver R, Stanford D, Storey L. Nasal dorsum. In: Paver R, Storey $L$, Stanford D, editor. Dermatologic surgery a manual of defect repair options. Adelaide: McGraw-Hill Medical; 2001. p. 56-69. 
14. Tissiani LAL, Alonso N, Carneiro MH, Bazzi K, Rocco M. Versatility of the bilobed flap. Rev Bras Cir Plást. 2011; 26: 411-7.

15. Oliveira FC Jr, Figueiredo JC, Piva AM. Techniques of cutaneuos nasal reconstruction in the aesthetical nasal subunits. Rev Bras Cir Craniomaxilofac. 2009; 12 : 105-8.

16. Brodland DG. Paramedian forehead flap reconstruction for nasal defects. Dermatol Surg. 2005; 31: 1046-52. doi: 10.1111/j.1524-4725.2005.31829.

17. Segundo B, Ribeiro A, Filho M, Ferreira L. Retalho médio-frontal tunelizado para reconstrução nasal e em canto de olho em único tempo: uma série de casos. Rev Med UFC. 2018;58:759.

18. Matos D, Goulão J. Retalho nasogeniano de transposição com pedículo superior - princípios e aplicação fundamentais. Rev Soc Port Dermatol Venereol. 2014; 72: 513-23.

19. Tavares, E, Rosa J. Reconstrução de defeito cirúrgico do nariz com enxerto de pele total colhido na região pré-auricular. Rev Soc Port Dermatol Venereol. 2012; 70: 495-8.

20. Kim YO, Park BY, Lee WJ. Aesthetic reconstruction of the nasal tip using a folded composite graft from the ear. Br J Plast Surg. 2004; 57:238-44. doi: 10.1016/j.bjps.2003.12.009. 